\title{
Rebuilding the front line
}

\author{
Sophie Cook clinical editor
}

The BMJ

GPs are overstretched, out-of-hours care is disorganised, and this week history was in the making, as junior doctors in England staged their first ever all-out strike (doi: 10.1136/bmj.i2404, doi:10.1136/bmj.i2382). The NHS front line is fragmented, strained, and in dire need of help.

"If general practice fails, the NHS fails," said Martin Roland and Sam Everington in a recent $B M J$ editorial

(doi:10.1136/bmj.i942). They called for substantial investment to redress the balance that has favoured hospital services in recent years. Along comes NHS England with an extra £2.4bn ( $€ 3 \mathrm{bn} ; \$ 3.5 \mathrm{bn}$ ) a year for primary care by $2020-21$ and the General Practice Forward View, which aims to boost the primary care workforce, cut bureaucracy, and restore GP services to health (doi:10.1136/bmj.i2297). Maureen Baker, president of the Royal College of General Practitioners, described the increased funding as "the most significant announcement for general practice since the 1960s" (doi:10. 1136/bmj.i2297).

In their follow-up editorial this week, Roland and Everington broadly applaud the proposals (doi:10.1136/bmj.i2357). But they warn that hospitals now need incentives to coordinate and collaborate with primary care and that overall funding of the
NHS is still grossly inadequate. Margaret McCartney casts doubt on the evidence base for some of the plans (doi:10.1136/bmj. i2366), citing this omission of evidence as one of two "elephant sized holes," the other being a failure to ditch things that don't work. "Doctors spending more time on bureaucracy, while clinical care is done by less qualified people, is not the change we need," she says.

Some of the cash is earmarked for funding extra GP capacity for seven day services, in and out of normal hours. Current out-of-hours care in England is confused and in serious need of refinement, conclude Martin Roland, Clifford Mann, and Neena Modi, who met recently for a $B M J$ roundtable debate (doi:10.1136/bmj.i2356). Is the answer record sharing, GP federations, senior staffing on the front line, or urgent care hubs? As senior doctors cover emergency care during this week's strike, and Jeremy Hunt stands firm on introducing the new contract, the junior doctor Alice Gerth, who has not participated in strike action, blogs about the "real risk of a schism between the sides of the picket line" (http://blogs.bmj.com/bmj).

New ideas and funds abound. Whether these will be enough to rebuild frontline services remains to be seen. 